\title{
Sex differences in clerical speed: Perceptual encoding vs. verbal encoding
}

\author{
RAYMOND L. MAJERES \\ Western Illinois University, Macomb, Illinois 61455
}

\begin{abstract}
Most interpretations of sex differences on clerical speed tests have emphasized the role of rapid perception of details and shifts in attention. Some have emphasized comparison and decision processes. Sex differences in speeded, successive matching were studied in four experiments with college students. The experimental task involved the successive identification of stimulus items presented in lists by tapping matching items on response cards. Sex differences were found to be related to response-card content and not to stimulus-list content. When the identification response involved tapping words, colors, or directional symbols, females were significantly faster than males; however, when the identification response involved tapping shapes, no significant sex differences were found. Results indicated that sex differences in some aspect of short-term memory may also be involved. Earlier interpretations of sex differences on speeded matching tasks in terms of such global concepts as perceptual speed are believed to be inadequate. An alternative explanation is discussed emphasizing verbal encoding, memory, and evaluation processes.
\end{abstract}

Attempts to explain sex differences on clerical matching tests and speeded, repetitive, and overlearned tasks, in general, have typically emphasized brain and hormonal differences (Broverman, Klaiber, Kobayashi, \& Vogel, 1968; Dawson, 1972; Gray \& Buffery, 1971). Others have tended to minimize the differences or question their reliability (Maccoby \& Jacklin, 1974). A substantial problem in this area seems to be a failure to describe accurately the perceptual and cognitive processes contributing to the reported sex differences.

Perceptual speed tests typically require the checking for similarities in lists of paired items (e.g., DGFHBDFHGB). Subjects are required to compare the items within each pair, indicating whether or not they match, and to continue quickly until all pairs, have been examined. The advantage of females over males on the perceptual speed tests is probably one of the most reliable sex differences in the cognitive domain (Anastasi, 1958; Garai \& Scheinfeld, 1968; Guilford, 1967; Maccoby, 1966; Tyler, 1965). For example, Schneidler and Paterson (1942), using the Minnesota Clerical Test, which requires the checking for identity between number and letter groups, found that only $18 \%$ of the male workers in the general population reached or exceeded the median of female workers. Sex differences were found at Grade Levels 5-12, with the difference increasing with age.

In more recent studies, Droege (1967), using a sample

This research was supported by a grant from the Western Illinois University Research Council. The assistance of graduate students William Martner and John Roach during data collection and the comments of Frank Fulkerson during paper preparation are gratefully acknowledged. Requests for reprints should be sent to Raymond L. Majeres, Department of Psychology, Western Illinois University, Macomb, Illinois 61455. of 20,000 adolescents from ages 14 to 16 years, found significant sex differences at all age levels on two speeded matching tasks. One task required subjects to compare names of firms for differences in style and spelling. On this test only $22 \%$ of the male subjects exceeded the mean of the female subjects. On a similar task using forms (tools and geometric forms), the comparable number was $33 \%$. Bennett, Seashore, and Wesman (1966), using tasks requiring the identification of matching letter-number combinations, reported significant sex differences in both speed and accuracy. More extensive reviews of this literature have been provided by Fairweather (1976) and Maccoby and Jacklin (1974). Tests believed to involve processes similar to those of the clerical speed tests (Guilford, 1967) are the Digit-Symbol and Coding subscales of the Wechsler intelligence scales. A female advantage has been reported from 4 years on into adulthood, although exceptions have been reported (cf. Fairweather, 1976; Hutt, 1972).

Interpretations of the sex difference in clerical speed have been based on early factor analytic studies. Investigators have reported that those tests involving speeded matching have consistently defined a factor called "perceptual speed." In most reviews of sex differences on speeded matching tasks, perceptual speed has been used to describe how males and females differ (Anastasi, 1958; Garai \& Scheinfeld, 1968; Tyler, 1965). It has been inferred that females must be superior to males in the rapid perception of details (encoding) and in making frequent shifts in attention. Although it is possible that sex differences in perceptual encoding and attentional shifts may be factors in explaining the sex differences in clerical speed, there are several other alternatives.

First, Guilford (1967) believes that the sex difference on the speeded matching tasks involves comparison and 
decision time as opposed to perceptual encoding time. He reports that on tests involving rapid recognition of fragmented stimuli, which according to Guilford are best characterized as involving perceptual speed, reliable sex differences have not been found. There appears to be nothing in the literature that would refute this point.

A second alternative is that the sex difference is related to female superiority in verbal abilities. Although whether there are reliable sex differences in verbal abilities is still not clear (Fairweather, 1976), when differences have been found they have typically favored females. Differences are frequently found on language usage tests, particularly around adolescence, and also on measures of "fluency." The tests of fluency require subjects to retrieve information from memory rapidly in line with certain constraints (e.g., name as many words as you can that end in "tion" or make as many words as possible out of a given set of letters). Maccoby and Jacklin (1974) have provided an extensive review of sex differences in verbal ability. A female advantage in verbal skills may facilitate the comparison and decision process. It is interesting in this regard that Guilford (1967) believes that sex differences on the speeded matching tests are related to test content. Guilford reports that sex differences typically are found when the materials are "symbolic units" (e.g., letters, words, and numbers).

An unfortunate characteristic of nearly all studies of sex differences in speeded matching is that the data are generally only descriptive, and systematic studies are rare. Nevertheless, Guilford has attempted to explain the sex difference on the clerical speed tests by attacking the popular belief that the sex difference is due to differences in perceptual encoding speed. First, Guilford (1967) believes that the sex difference is not general, but is specific to symbolic materials. Guilford's distinction is not between verbal and figural stimuli, but appears to approach a distinction between perceptual matching vs. mediated or associational matching. What is important is how the subjects process the stimulus information, rather than the nature of the stimuli per se. For example, although letters are figural they are most frequently processed as symbols. The second point is that sex differences are related to comparison and decision speed rather than perceptual encoding speed. Presumably the evaluation process would be affected by such things as the nature of the encoding and some aspects of short-term memory. The purpose of the present research was to investigate these assertions.

\section{EXPERIMENT 1}

In an early study, Dubois (1939) found that the reported sex differences in naming repeated colors (consecutive patches of red, green, black, blue, and yellow appearing in lists) is even greater when the subjects were asked to tap matching colors on a response card rather than to utter the names. Dubois interpreted his results on the matching task in terms of sex differences in speed of color encoding. Of course, this interpretation is reminiscent of the frequent emphasis on rapid recognition or perceptual encoding factors on clerical speed tests. Also, since the sex differences observed by Dubois involved colors, this questions Guilford's hypothesis that task content must involve symbolic units in order for the sex differences to be observed.

To determine whether perceptual encoding (in this case, of colors) may be a central factor in accounting for the sex differences on speeded matching tasks, stimulus lists varying in the percentage of colors were used. Progressively decreasing the proportion of colors by substituting color names would decrease the amount of color encoding and increase the amount of word encoding required. To explore sex differences in color encoding further, a color-tapping condition, as used by Dubois (1939), and a color-name-tapping condition were included in the present experiment. The color-nametapping condition provided a means of further reducing the degree of color encoding in making the matching response. On the one hand, according to Dubois' hypothesis, since this strategy systematically reduces the importance of color encoding on performance, it should lead to a reduction in the size of the sex difference. On the other hand, the addition of symbolic units (words) to the lists and response cards, according to Guilford, should lead to the opposite conclusion. That is, sex difference should be greater when there are more words vs. colors involved in the tasks. Significant sex differences across all conditions would indicate a female superiority in the encoding of both colors and words, thus supporting the hypothesis of sex differences in perceptual encoding.

\section{Method}

Subjects. Forty-eight undergraduate volunteers, 24 males and 24 females, from introductory psychology classes at a midwestern state university served as subjects and were given course credit for their participation.

Design and materials. The design was a 2 by 2 by 4 by 4 multifactor repeated measures plan, with sex and response conditions as between-subjects variables and stimulus lists and trial blocks as within-subjects variables. Equal numbers of males and females were randomly assigned to each of the two response conditions. In one response condition, subjects tapped $3 \times 5$ in. cards with a red, green, or blue patch in the center as the identifying response. In the other condition, subjects tapped the same sized cards with color names printed on them.

All subjects were presented four stimulus lists: $100 \%$ color (40 rectangles of color), $70 \%$ color $(12$ colors were replaced with their respective color names), $40 \%$ color (24 colors were replaced by color names), and $0 \%$ color (all color names). Each list consisted of two 20-item columns on an $8.5 \times 11$ in. card. The color lists of Sichel and Chandler (1969) were used with color names typed (pica) on white patches and added to the lists as required. There were two forms of each of the four lists, differing only in random order.

Procedure. Each subject of each sex was randomly assigned 
Table I

Mean Time (seconds) to Match 40 List Items by

Tapping Corresponding Color-Name and Color Response Cards

\begin{tabular}{|c|c|c|c|c|c|c|c|}
\hline \multirow{2}{*}{$\begin{array}{l}\text { \% Colors } \\
\text { in Stimu- } \\
\text { lus List }\end{array}$} & \multirow{2}{*}{$\begin{array}{l}\text { Tapping } \\
\text { Response }\end{array}$} & \multirow[b]{2}{*}{ Sex } & \multicolumn{4}{|c|}{ Trial Block } & \multirow{2}{*}{$\begin{array}{c}\text { Over- } \\
\text { all }\end{array}$} \\
\hline & & & 1 & 2 & 3 & 4 & \\
\hline \multirow{2}{*}{$100 \%$} & Color Name & $\begin{array}{l}\text { Male } \\
\text { Female }\end{array}$ & $\begin{array}{l}30.4 \\
28.5\end{array}$ & $\begin{array}{l}31.0 \\
29.2\end{array}$ & $\begin{array}{l}27.0 \\
26.3\end{array}$ & $\begin{array}{l}28.6 \\
27.6\end{array}$ & $\begin{array}{l}29.3 \\
27.9\end{array}$ \\
\hline & Color & $\begin{array}{l}\text { Male } \\
\text { Female }\end{array}$ & $\begin{array}{l}27.0 \\
22.5\end{array}$ & $\begin{array}{l}27.0 \\
22.9\end{array}$ & $\begin{array}{l}24.6 \\
20.2\end{array}$ & $\begin{array}{l}25.7 \\
21.4\end{array}$ & $\begin{array}{l}26.1 \\
21.8\end{array}$ \\
\hline \multirow{2}{*}{$70 \%$} & Color Name & $\begin{array}{l}\text { Male } \\
\text { Female }\end{array}$ & $\begin{array}{l}36.2 \\
34.5\end{array}$ & $\begin{array}{l}36.1 \\
32.1\end{array}$ & $\begin{array}{l}33.3 \\
31.2\end{array}$ & $\begin{array}{l}32.4 \\
31.8\end{array}$ & $\begin{array}{l}34.5 \\
32.4\end{array}$ \\
\hline & Color & $\begin{array}{l}\text { Male } \\
\text { Female }\end{array}$ & $\begin{array}{l}31.6 \\
26.0\end{array}$ & $\begin{array}{l}30.8 \\
25.0\end{array}$ & $\begin{array}{l}29.8 \\
24.2\end{array}$ & $\begin{array}{l}29.8 \\
25.2\end{array}$ & $\begin{array}{l}30.5 \\
25.1\end{array}$ \\
\hline \multirow{2}{*}{$40 \%$} & Color Name & $\begin{array}{l}\text { Male } \\
\text { Female }\end{array}$ & $\begin{array}{l}35.4 \\
31.4\end{array}$ & $\begin{array}{l}35.8 \\
33.0\end{array}$ & $\begin{array}{l}31.6 \\
32.2\end{array}$ & $\begin{array}{l}31.7 \\
31.8\end{array}$ & $\begin{array}{l}33.6 \\
32.1\end{array}$ \\
\hline & Color & $\begin{array}{l}\text { Male } \\
\text { Female }\end{array}$ & $\begin{array}{l}29.7 \\
24.3\end{array}$ & $\begin{array}{l}30.2 \\
23.9\end{array}$ & $\begin{array}{l}26.6 \\
23.2\end{array}$ & $\begin{array}{l}28.9 \\
24.1\end{array}$ & $\begin{array}{l}28.8 \\
23.9\end{array}$ \\
\hline \multirow{2}{*}{$0 \%$} & Color Name & $\begin{array}{l}\text { Male } \\
\text { Female }\end{array}$ & $\begin{array}{l}31.6 \\
28.8\end{array}$ & $\begin{array}{l}28.0 \\
28.9\end{array}$ & $\begin{array}{l}27.9 \\
27.2\end{array}$ & $\begin{array}{l}27.4 \\
25.9\end{array}$ & $\begin{array}{l}28.7 \\
27.7\end{array}$ \\
\hline & Color & $\begin{array}{l}\text { Male } \\
\text { Female }\end{array}$ & $\begin{array}{l}27.8 \\
22.2\end{array}$ & $\begin{array}{l}28.4 \\
23.3\end{array}$ & $\begin{array}{l}27.0 \\
22.5\end{array}$ & $\begin{array}{l}25.4 \\
22.9\end{array}$ & $\begin{array}{l}27.2 \\
22.7\end{array}$ \\
\hline Overall & & & 29.2 & 29.1 & 27.2 & 27.5 & \\
\hline
\end{tabular}

to one of the 24 possible orders of the four stimulus conditions (100\%, $70 \%, 40 \%$, and $0 \%$ color). Each subject was given one block of trials with the lists occurring in each subject's original order; then the lists were presented again, but in reverse order. The entire sequence was then repeated so that each list was presented a total of four times, once within each of the four trial blocks.

The response cards were vertically arranged on the right side of the list card (left side for left-handed subjects), and subjects rapidly and sequentially identified the stimulus list items by tapping the response cards with the stylus. The spatial order of the three response cards (top, middle, bottom position) was changed after each trial to minimize the role of memory in responding. With a stopwatch, times were recorded to the nearest $.10 \mathrm{sec}$ from the first response to the last. Subjects were asked to identify all items as rapidly as possible and to correct all errors.

\section{Results and Discussion}

Dubois' (1939) report of large sex differences in identifying colors under color-tapping conditions was replicated. In fact, the analysis of variance yielded a significant main effect for $\operatorname{sex}[F(1,44)=9.25, \mathrm{p}<.005]$, with females being consistently faster than males across all conditions as shown in Table 1. However, the type of response did tend to affect the size of the sex difference [Sex by Response: $\mathrm{F}(1,44)=2.50, \mathrm{p}<.12, \mathrm{MSe}=$ 202.90]. The Neuman-Keuls procedure indicated that the females were significantly faster $(p<.01)$ than the males under the color-tapping condition. Females also tended to be faster under the color-name-tapping condition, though the difference was not significant, thereby providing some support for Dubois' hypothesis. But Dubois' interpretation that the sex difference is due to female superiority in color encoding received no support from the data for the different stimulus list conditions. The proportion of colors in the stimulus lists did not influence the size of the observed sex differences [Sex by Stimulus Lists: $F(3,132)<1]$. Since sex differences were observed under all of the stimulus conditions when subjects were color tapping, Guilford's emphasis on the importance of symbolic content also seems questionable, although subjects may readily resort to verbal encoding of colors and deal with them in these terms.

There was evidence that the females adjusted to the demands of the task more quickly and then maintained higher levels of performance than males. There was a significant Sex by Trial Blocks interaction $[F(3,132)=$ $3.19, \mathrm{p}<.05, \mathrm{MSe}=8.42 \mathrm{~J}$, with sex differences being significantly larger on the first three trial blocks and then decreasing (Neuman-Keuls, ps $<.01$ ). Females were still significantly faster on the last trial block $(\mathrm{p}<.05)$. Females began with faster time and average improvement was slight, $.98 \mathrm{sec}$, while the average improvement for males was greater, $2.47 \mathrm{sec}$.

Type of response $[\mathrm{F}(1,44)=23.78, \mathrm{p}<.001]$, stimulus list $[\mathrm{F}(3,132)=81.17, \mathrm{p}<.001]$, and trial blocks $[F(3,132)=25.52, p<.001]$ main effects were also significant. In addition, lists containing both color and color names required more identification time than the all-color and all-color-name stimulus lists, and this difference was greater for the color-name-tapping condition than for the color-tapping condition [Response by Stimulus List: $F(3,132)=8.05, p<.001$, MSe $=11.32]$.

The major finding was a large and significant sex main effect. One possible explanation of this significant sex main effect is that females can tap faster than males. To test this hypothesis, 24 additional subjects, 12 males and 12 females, alternately tapped two $10 \times 10 \mathrm{~cm}$ plates, $8 \mathrm{~cm}$ apart, with a stylus. Subjects were asked to tap as rapidly as possible until instructed to stop (40 taps). The taps were electronically counted. The mean times to make the 40 taps were $6.96 \mathrm{sec}$ for males and $7.55 \mathrm{sec}$ for females $[\mathrm{t}(22)=1.95, \mathrm{p}<.10]$. Males have been reported to be significantly faster than females in tapping rate where precision is not important (e.g., Barnsley \& Rabinowitz, 1970). Responses in the original experiment, as well as for the supplementary data, did not require precise movements. Hence, there is little to support the hypothesis that the sex main effect is the result of faster tapping speeds for females.

Another possible source of female superiority, in line with the perceptual speed hypothesis, may have involved a sex difference in visual scanning or at tentional shifts. A Neisser (1967) type visual search task was used to test this possibility. Subjects, 24 female and 24 male, were asked to scan lists of colors, color names, shapes, or shape names. The shapes were circles, squares, and triangles. Rather than identify each color, shape, or word in a list, subjects were asked to tap each time they saw a single designated list item. Hence, subjects were searching for a single item and tapping whenever an instance 
occurred. There were three trials on each of the four lists. No significant sex difference occurred [males, $6.8 \mathrm{sec}$; females, $5.6 \mathrm{sec} ; \mathrm{F}(1,22)=1.96]$, nor were any of the interactions significant. The visual search task places a premium on rapid shifts in attention and perceptual encoding. However, comparison and decision processes and aspects of short-term memory may also be involved. The failure to find a reliable sex difference under these conditions is not consistent with the hypothesis of sex differences in perceptual encoding and at tentional shifts.

\section{EXPERIMENT 2}

Reliable sex differences in repetitive color-to-color, color-to-word, and word-to-word matching were found in Experiment 1. The results indicated that the observed sex differences were not related to sex differences in tapping speed or in ability to make rapid attentional shifts. The size of the sex difference was not related to the content of the stimulus lists, though the presence or absence of color on the response cards appeared to be related to sex differences in performance. The finding that response requirements were related to sex, while stimulus conditions were not, may be consistent with Guilford's (1967) assertion that sex differences on speeded repetitive tasks involve processing differences after perceptual encoding. However, Guilford's belief that the female advantage depends upon symbolic task content was not supported in Experiment 1. Response card conditions involving colors did produce significant sex differences. However, color may be peculiar to the general rule. The purpose of the second experiment was to determine whether the response card or stimulus list content contributes to the sex difference, and also whether the symbolic content of the response cards is critical. Geometric shapes and shape names were used in place of colors and color names.

\section{Method}

Subjects. Forty-eight undergraduate volunteers, 24 males and 24 females, from introductory psychology classes at a midwestern state university served as subjects and were given course credit for their participation.

Procedure. The geometric shapes, square, circle, and triangle, and their respective names were used. The shapes and shape names were presented in lists and on response cards using the same format as was used for the color and color-name lists of Experiment 1 . The design in all other ways was exactly the same as in the first experiment.

\section{Results and Discussion}

The sex main effect for a 2 by 2 by 4 by 4 analysis of variance was not significant $[F(1,44)=3.30, p<.07]$, although female subjects generally tended to be faster than male subjects, as shown in Table 2 . The Sex by Response by Stimulus List interaction was significant $[\mathrm{F}(3,132)=4.32, \mathrm{p}<.01, \mathrm{MSe}=11.22]$. The NeumanKeuls procedure indicated that there were no significant
Table 2

Mean Time (seconds) to Match 40 List Items by Tapping Corresponding Shape-Name and Shape Response Cards

\begin{tabular}{|c|c|c|c|c|c|c|c|}
\hline \multirow{2}{*}{$\begin{array}{l}\text { \% Shapes } \\
\text { in Stimu- } \\
\text { lus List }\end{array}$} & \multirow{2}{*}{$\begin{array}{l}\text { Sapping } \\
\text { Response }\end{array}$} & \multirow[b]{2}{*}{ Sex } & \multicolumn{4}{|c|}{ Trial Block } & \multirow{2}{*}{$\begin{array}{c}\text { Over- } \\
\text { all }\end{array}$} \\
\hline & & & 1 & 2 & 3 & 4 & \\
\hline \multirow{2}{*}{$100 \%$} & Shape Name & $\begin{array}{l}\text { Male } \\
\text { Female }\end{array}$ & $\begin{array}{l}34.6 \\
30.9\end{array}$ & $\begin{array}{l}33.3 \\
30.0\end{array}$ & $\begin{array}{l}31.7 \\
29.8\end{array}$ & $\begin{array}{l}32.3 \\
29.3\end{array}$ & $\begin{array}{l}33.0 \\
30.0\end{array}$ \\
\hline & Shape & $\begin{array}{l}\text { Male } \\
\text { Female }\end{array}$ & $\begin{array}{l}27.2 \\
26.7\end{array}$ & $\begin{array}{l}26.3 \\
24.6\end{array}$ & $\begin{array}{l}25.1 \\
24.1\end{array}$ & $\begin{array}{l}23.3 \\
23.2\end{array}$ & $\begin{array}{l}25.4 \\
24.6\end{array}$ \\
\hline \multirow{2}{*}{$70 \%$} & Shape Name & $\begin{array}{l}\text { Male } \\
\text { Female }\end{array}$ & $\begin{array}{l}44.5 \\
36.6\end{array}$ & $\begin{array}{l}41.3 \\
35.3\end{array}$ & $\begin{array}{l}37.7 \\
33.3\end{array}$ & $\begin{array}{l}37.3 \\
32.9\end{array}$ & $\begin{array}{l}40.2 \\
34.5\end{array}$ \\
\hline & Shape & $\begin{array}{l}\text { Male } \\
\text { Female }\end{array}$ & $\begin{array}{l}33.8 \\
31.7\end{array}$ & $\begin{array}{l}31.6 \\
31.2\end{array}$ & $\begin{array}{l}29.3 \\
29.8\end{array}$ & $\begin{array}{l}31.1 \\
29.5\end{array}$ & $\begin{array}{l}31.4 \\
30.6\end{array}$ \\
\hline \multirow{2}{*}{$40 \%$} & Shape Name & $\begin{array}{l}\text { Male } \\
\text { Female }\end{array}$ & $\begin{array}{l}44.8 \\
35.2\end{array}$ & $\begin{array}{l}40.8 \\
34.0\end{array}$ & $\begin{array}{l}37.3 \\
33.5\end{array}$ & $\begin{array}{l}35.9 \\
33.3\end{array}$ & $\begin{array}{l}39.7 \\
34.0\end{array}$ \\
\hline & Shape & $\begin{array}{l}\text { Male } \\
\text { Female }\end{array}$ & $\begin{array}{l}33.7 \\
33.6\end{array}$ & $\begin{array}{l}32.9 \\
33.5\end{array}$ & $\begin{array}{l}29.8 \\
31.5\end{array}$ & $\begin{array}{l}30.9 \\
30.5\end{array}$ & $\begin{array}{l}31.8 \\
32.3\end{array}$ \\
\hline \multirow{2}{*}{$0 \%$} & Shape Name & $\begin{array}{l}\text { Male } \\
\text { Female }\end{array}$ & $\begin{array}{l}36.7 \\
30.4\end{array}$ & $\begin{array}{l}34.5 \\
29.2\end{array}$ & $\begin{array}{l}34.0 \\
29.6\end{array}$ & $\begin{array}{l}31.9 \\
30.0\end{array}$ & $\begin{array}{l}34.3 \\
29.8\end{array}$ \\
\hline & Shape & $\begin{array}{l}\text { Male } \\
\text { Female }\end{array}$ & $\begin{array}{l}30.1 \\
29.0\end{array}$ & $\begin{array}{l}29.8 \\
28.4\end{array}$ & $\begin{array}{l}28.5 \\
29.5\end{array}$ & $\begin{array}{l}26.6 \\
27.1\end{array}$ & $\begin{array}{l}28.8 \\
28.5\end{array}$ \\
\hline Overall & & & 33.7 & 32.3 & 30.9 & 30.3 & \\
\hline
\end{tabular}

sex differences under the shape-tapping condition. However, females were significantly faster than males $(p<.05)$ on the word-tapping condition for all stimulus conditions except the $100 \%$ shape stimulus list, where the difference was in the same direction but nonsignificant.

The Sex by Response by Trial Blocks $[F(3,132)=$ $3.05, \mathrm{p}<.05, \mathrm{MSe}=12.33]$ and the Sex by Trial Blocks $[F(3,132)=3.75, p<.02]$ interactions were also significant. Males showed greater improvement than females, with significant improvement on Trial Blocks 1,2 , and 3 (ps $<.01$ ). Only the difference between Trial Blocks 3 and 4 was not significant. For female subjects, consecutive trial block differences were not significant, although all other trial block differences were significant (ps $<.05$ ).

The degree of improvement was reliably greater for the males, especially on Trial Blocks 1 and 2 on the word-tapping condition (ps $<.01$ ). Although males showed greater improvement than females over trials on the shape-tapping condition, the differences were small and nonsignificant. The results indicate that the magnitude of the sex difference and the sex difference in trial block effects were greater when the tapping conditions involved symbols (words) rather than figures (shapes). It should be emphasized that, as indicated in Experiment 1 , the content of the response cards, not of the stimulus lists, was the relevant factor for sex differences in responding.

Although females were faster than males (significant main effect) in Experiment 1 on both color tapping and color-name tapping, the sex difference for the colorname- (word) tapping condition was smaller and fell short of statistical significance using the Neuman-Keuls 
procedure. In the present experiment in the shape-name(word) tapping condition, the sex difference was significant. There is further evidence in Experiments 3 and 4 that reliable sex differences are typically observed under word-tapping conditions.

\section{EXPERIMENT 3}

The results of Experiment 2 tend to support Guilford's (1967) hypothesis that the symbolic vs. figural distinction may in some way be important in understanding the sex difference on speeded matching tasks. Experiment 1 indicated that one exception to this hypothesis is color content. However, both experiments indicated that it is the content of the response cards, not of the stimulus list, that appears to be critical. Experiment 3 was a further attempt to determine the importance of the type of material on the response card.

In this experiment symbols, geometric shapes indicating direction, were used. According to Guilford (1967), significant sex differences should be found since the content, although involving a figure, is being used to symbolize direction. However, unlike most common symbols, these symbols are not overlearned as are letters and digits. It may be that degree of overlearning vs. the symbolic nature of the task content is important to the sex difference in performance.

\section{Method}

Subjects. Thirty males and 30 female undergraduate volunteers from introductory psychology classes at a midwestern state university served as subjects and were given course credit for their participation.

Procedure. A single shape, a square with one side absent, was used in three different orientations: opening to the left, to the right, and down. The orientation names "left," "right," and "down" and the corresponding figures were used to construct lists analogous to two of those used in Experiment 1. One list consisted of shapes in the three different orientations and the other of orientation names. Each list consisted of two columns of 20 items which were read from left to right and down. There were two forms of each list, differing only in random order. All subjects received six trial blocks containing the two stimulus lists with the list order being alternated, half beginning with shapes indicating orientation and half with the orientation names.

Equal numbers of males and females were assigned to two response conditions: tapping the words "left," "right," and "down" or tapping the respective shapes designating these orientations. The procedures were otherwise like those used in Experiments 1 and 2.

\section{Results and Discussion}

A 2 by 2 by 2 by 6 analysis of variance, with sex and shape orientation vs. orientation-name tapping as between-subjects variables and lists (orientation vs. orientation-name lists) and trial blocks as within-subjects variables, yielded a significant sex main effect $[F(1,56)=$ $4.39, \mathrm{p}<.05$, MSe $=504.70]$. In the present experiment, where shapes were used as symbols indicating orientation, significant sex differences were found with females being faster than males, $35.4 \mathrm{sec}$ and $38.9 \mathrm{sec}$, respectively. This was the case for both tapping orientation names (34.6 vs. 38.2) and tapping shapes indicating orientation (36.2 vs. 39.5$)$ (Neuman-Keuls, ps $<.05$ ). Stimulus List conditions $[F(1,56)=313.85, \mathrm{p}<.001]$, trial blocks $[\mathrm{F}(5,280)=50.0, \mathrm{p}<.001]$, Response by Stimulus Lists $[\mathrm{F}(1,56)=21.38, \mathrm{p}<.001, \mathrm{MSe}=44.79]$, and Stimulus by Trial Blocks $[\mathrm{F}(5,280)=2.98, \mathrm{p}<.01$, $\mathrm{MSe}=16.09]$ main effects and interactions were also significant. Performance was faster on the word-stimulus list, in general, and was faster when word tapping than when tapping shapes indicating orientation (30.8 $\mathrm{sec}$ vs. $34.6 \mathrm{sec}, \mathrm{p}<.05$, Neuman-Keuls). With the shapestimulus list, there was no significant difference between type of response, word or shape tapping (42.0 and 41.0, respectively). Practice effects were greater for orientation than for the word-stimulus lists. There were no significant interactions involving the sex variable.

It is noteworthy that, although in this experiment under the tapping-shapes-indicating-orientation condition sex differences were found, in Experiment 2, where subjects were also tapping shapes, significant sex differences were not found. Since the matching could be done, at least for the shape-to-shape matching, using only figural information, it may be assumed that in the present experiment the shapes were dealt with in terms of the verbal codes, "left," "right," and "down," or some other more conceptual scheme, rather than as simple geometric shapes. Since the shapes differed only in orientation, labels may have proved more efficient than trying to make comparisons on a figural basis (Royer, 1971). A tentative hypothesis is that the observed sex differences may ultimately be accounted for in terms of type of encoding and its impact on subsequent processing.

\section{EXPERIMENT 4}

Taken together, the results of Experiments 1, 2, and 3 indicate that task content, at least on the response cards, is relevant to sex differences in performance. Colors, words, and shapes indicating orientation, when used on the response cards, all resulted in significant sex differences. When shapes-as-shapes were used on the response cards, no significant sex differences were found. It should be remembered that, while the size of the sex difference did vary as a function of responsecard content, the direction of the sex difference was consistently in favor of females. The type of responsecard content does not appear to be a matter of a qualitative distinction, symbolic vs. figural, but of a quantitative distinction probably involving type of encoding and its impact on response execution.

The fact that response-card content was sex related while stimulus-list content was not is rather puzzling. One possible explanation of this stems from the observation that subjects do not look at the response cards in 
making each response. From observation, it appears that subjects learn the card locations and, after a time, tap without looking at the cards except for regular glances to check the accuracy of their responses. The fact that response-card content has been found to influence the size of the observed sex differences suggests that some aspect of memory may be implicated in the observed sex differences. One reason the females did so well on the present task may be due to the frequently reported female superiority on some types of memory tasks, especially those involving verbal content (Anastasi, 1958; Guilford, 1967; Tyler, 1965).

Maccoby and Jacklin (1974) conclude that girls show somewhat better memory for verbal content, whereas boys may have an advantage with designs. There is also some evidence of sex differences in a type of recognition memory involved in verbal discrimination learning. On this task pairs of words are presented with one of the words designated as "right" and the other as "wrong." Typically, the subjects' task is to recognize which member of each pair is "right" when the pairs are later presented. Females have been found to make fewer errors in learning to criterion than males (Fulkerson \& Johnson, 1971). This result was again found in a later study (Fulkerson \& Prindaville, 1973). However, in tests of memory span using digits, as in the Digits Forward subscale of the Wechsler intelligence scales, as well as in paired associate learning and numerous other learning tasks, sex differences are rarely observed (Maccoby \& Jacklin, 1974).

Subjects remembering the response-card order most readily would have an advantage on the present tasks, since they would not have to look at the response cards as often. If the order was not changed, both male and female subjects would have ample opportunity to learn the spatial order of the three cards. Holding the card order constant would tend to minimize the alleged memory advantage of the females. The purpose of this experiment was to determine whether the sex differences observed in Experiments 1,2, and 3 are related to sex differences in some aspect of short-term memory.

\section{Method}

Subjects. Forty-eight undergraduate volunteers, half males and half females, from introductory psychology classes at a midwestern state university served as subjects and were given course credit for their participation.

Procedure. Subjects identified colors using the $100 \%$ color lists with the response cards placed vertically along the side of the stimulus lists as in Experiment 1. For half of the male and female subjects, the spatial order (top, middle, bottom position) of the three response cards was changed to a new random order after each list. The remaining subjects identified the colors using a fixed response-card order. The specific response-card order for the fixed-order condition varied from subject to subject with all possible orders occurring equally of ten.

To study the role of response-card content further, four different response conditions were used: three color cards, two color cards and one word card, one color card and two word cards, and three word cards. In the fixed-order condition or no- change condition, the order, for example, red-green-blue, always occurred, but the way these color concepts were represented was varied. The concept "red" can be represented as a color patch or as a word, and likewise for the other two colors. Three color cards means the response cards were three color-patch cards, two color cards and one word card means that two of the cards were color-patch cards and one had the name of the color on it, and so on. To control for the order of these four response conditions (whether the subject responded first with the three color-patch cards, then two color-patch and one word card, etc.) one male and one female subject were assigned to each of the 24 permutations of these four response conditions. Each subject's assigned order was repeated three times (three trial blocks), giving three trials per response condition.

\section{Results and Discussion}

A 2 by 2 by 4 by 3 analysis of variance, with sex and change vs. no-change of spatial order as between-subjects variables and response-card conditions (ratio of color patches to words) and trial blocks as within-subjects variables, yielded a significant sex main effect $[F(1,44)=$ $8.09, \mathrm{p}<.01$ ] , with females generally faster than males, as shown in Table 3 . However, the major hypothesis involved the Sex by Change interaction, which was not significant $[\mathrm{F}(1,44)=2.65, \mathrm{p}<.11, \mathrm{MSe}=232.41]$. Given the a priori nature of this prediction, further analysis using the Neuman-Keuls procedure did indicate that females were significantly faster than males under the change condition $(p<.01)$, but there was no significant sex difference under the no-change condition (although females did tend to be faster in all conditions).

The Change by Response interaction was significant $[\mathrm{F}(3,132)=3.78, \mathrm{p}<.02, \mathrm{MSe}=8.28]$. Under the change condition, which forced subjects to attend to the response-card content, there were signficant differences among all of the response conditions (ps $<.01$ ), with task performance times decreasing as the number of color-patch cards increased. Under the no-change condition, where subjects could remember the location of the color concepts and did not have to look at the card content as frequently, the difference between the two-color-patches-one-word and the three-color-patches condition and between the two-words-one-color-patch

Table 3

Mean Time (Seconds) to Match a List of 40 Colors by Tapping Corresponding Colors, Words, or Combinations With and Without Change of Card Order

\begin{tabular}{|c|c|c|c|c|c|}
\hline \multirow[b]{2}{*}{ Group } & \multicolumn{4}{|c|}{ Tapping Condition } & \multirow[b]{2}{*}{ Overall } \\
\hline & 3 Colors & $\begin{array}{l}2 \text { Colors } \\
1 \text { Word }\end{array}$ & $\begin{array}{l}1 \text { Color } \\
2 \text { Words }\end{array}$ & 3 Words & \\
\hline $\begin{array}{c}\text { No Change } \\
\text { Males } \\
\text { Females }\end{array}$ & $\begin{array}{l}23.9 \\
22.7\end{array}$ & $\begin{array}{l}24.6 \\
23.6\end{array}$ & $\begin{array}{l}26.7 \\
25.1\end{array}$ & $\begin{array}{l}27.3 \\
25.2\end{array}$ & $\begin{array}{l}25.625 \\
24.150\end{array}$ \\
\hline $\begin{array}{l}\text { Change } \\
\text { Males } \\
\text { Females }\end{array}$ & $\begin{array}{l}25.5 \\
20.1\end{array}$ & $\begin{array}{l}26.6 \\
21.8\end{array}$ & $\begin{array}{l}29.3 \\
23.3\end{array}$ & $\begin{array}{l}31.5 \\
24.9\end{array}$ & $\begin{array}{l}28.224 \\
22.525\end{array}$ \\
\hline Overall & 23.05 & 24.15 & 26.1 & 27.225 & \\
\hline
\end{tabular}


and the three-word condition were not significant. The remaining differences were significant $(\mathrm{ps}<.05)$. The net result was a weaker response condition effect under the no-change condition, presumably because subjects were relying on memory of location and did not need to process card content as frequently as under the change condition. The Sex by Trial Blocks interaction was not as significant, though there were significant trial block effects $[F(2,88)=89.55, p<.001]$. The results favor the hypothesis that female superiority on the present task is related to sex differences in short-term memory processes. However, given the level of significance on the Sex by Change interaction, this conclusion remains tentative.

\section{GENERAL DISCUSSION}

Popular accounts of sex differences in clerical speed tests have emphasized perceptual factors (Anastasi, 1958; Tyler, 1965). However, Guilford (1967) has suggested that the sex difference is specific to symbolic materials. and that the important process or operation is evaluation rather than perceptual encoding.

None of the present experiments indicated a relationship between stimulus-list content and sex, an unexpected result if sex differences in perceptual encoding are critical. For example, since colors can be encoded more rapidly with a rather low level of analysis relative to words, one might expect sex differences to be less apparent with colors than with words. Since words require more analysis time and thus provide ample opportunities for females to demonstrate their superiority, one might expect larger sex differences for words relative to colors. Also, on a visual search task, involving rapid perceptual encoding and shifts in attention, significant sex differences were not observed.

However, the content of the response cards was found to be sex related. In Experiment 1, where the sex main effect was significant, the sex difference was larger when subjects were tapping colors than when tapping words. In Experiment 2, sex differences were found under word tapping but not under shape tapping. In Experiment 3, where shapes were used to indicate direction, sex differences were found for both figures indicating orien tation and for words.

The finding that the size of the sex difference was dependent on the content of the response cards, while stimulus-list content and performance on the visual search task were not, provides some support for Guilford's (1967) hypothesis that sex differences on the clerical speed tests might best be described in terms of the evaluation of symbolic units vs. perceptual speed (Anastasi, 1958; Tyler, 1965) or perceptual-motor speed (Maccoby \& Jacklin, 1974). However, there are a number of possible alternative explanations.

There are several reports directly related to an analysis of the sex difference on speeded repetitive matching tasks. For example, Fairweather and Hutt (1972) reported a female advantage over males at 7,9, and approximately 11 years of age on a serial-choice reaction time task. Digits (sets of 2,4 , or 8 ) were consecutively presented (R-S interval, $200 \mathrm{msec}$ ) and subjects responded by tapping one of 2,4 , or 8 corresponding response keys depending upon the stimulus set size. Using information theory, the results were interpreted in terms of sex differences in information processing capacity. Fairweather and Hutt observed that others typically have not found sex differences in information processing because of the limited response selections used (pointing to a target, saying "yes" or "no," or making same-different judgments). Congruent with present results, they concluded that the nature of the response requirements are critical in observing sex differences on tasks of this type.

Royer (1971) found performance on the Digit Symbol Test (DST), a subtest of the Wechsler Adult Intelligence Scale, to be linearly related to an index of information processing derived from information theory. If, as Fairweather and Hutt (1972) suggest, there are sex differences in information processing capacity, one would expect to find sex differences on the DST. In fact, sex differences in favor of females have repeatedly been reported on the DST (cf. Fairweather, 1976; Hutt, 1972). With respect to the current findings, Guilford (1967) regards the DST as involving, in part, the same processes as the clerical speed tests, plus a memory factor. Both of these aspects, speeded evaluation and memory, have been implicated in performance on the present matching tasks.

Estes (1974), in an analysis based on Royer's (1971) data, suggests that the skill in the DST involves a verbalencoding process as a major component. This interpretation suggests that females may have some advantage in the utilization of verbally encoded material, especially where such encoding facilitates the organization and execution of one of several responses. This interpretation may provide an explanation of several of the present results.

First, females did consistently better than males when the response conditions involved tapping words. Sex differences were substantial for shape-name tapping and color-name tapping, though less so for color-name tapping. The smaller sex difference for color-name tapping is not due to less efficient performance by females, however, but to the very efficient performance by males. For example, the average time for males for color-name tapping was $31.5 \mathrm{sec}$, while for tapping shape names and orientation names the means were $36.8 \mathrm{sec}$ and $39.5 \mathrm{sec}$, respectively. The smallest sex differences were observed when subjects were tapping geometric shapes. Whatever encoding is required to discriminate among shapes as response alternatives, the females either lose their advantage, or, perhaps, males excel under such requirements. This result is consistent 
with the finding of Bennett, Seashore, and Wesman (1966) that on speeded matching of tool shapes and geometric forms the sex difference is less than when comparing the names of business firms. Since female superiority was observed with colors on the response card, does this mean that females have some special advantage in verbally encoding colors? This is clearly a possibility, since there is substantial information that females can name common colors under speeded, repetitive conditions faster than males (Jenson \& Rohwer, 1966).

Second, more efficient use of verbally encoded material by the females over the males also may facilitate the evaluation process. For example, females were faster than males when response-card orders were changed in Experiment 4 . This change condition would necessitate more rechecking relative to the no-change-of-order condition, since subjects would be less confident of their responses under the change condition. The results of Experiment 4 indicate that not only did more checking occur, as evidenced by the greater influence of responsecard content on performance under the change condition, but that females did better than males under this condition. Likewise, it was found that when all subjects had ample opportunity to learn the location of each of the response cards (the no-change condition), no significant sex differences were found. Presumably, sustained practice with the cards in a given order resulted in less checking for accuracy. This finding suggests that more efficient use of verbal codes by females may facilitate the rechecking process itself.

Third, the interpretation in terms of sex differences in the use of verbal codes may also explain the sex differences in trial effects in Experiments 1 and 2. If it is assumed that ease of verbal encoding facilitates representation of the responses in memory, leading to both efficient memory and efficient checking, then females would have an advantage that would be most apparent on early trials. With practice, the response-card order would be learned by most subjects and memory differences would become less important. Hence, sex differences in memory would be most apparent during the early trials. Substantial female superiority was found on the early word-tapping trials of Experiments 1 and 2 . When response-card content is not readily verbally encoded or involves some other type of codes, as would have been the case for the shapes on response cards in Experiment 2 and directional signs in Experiment 3, the large early advantage of females over males would not be anticipated and was not found.

A limitation of the present research is that data on uncorrected errors are lacking. Errors were so infrequent in the early collection of data that attempts to record errors were terminated. Also, the present method does not lend itself to the accurate assessment of such errors. However, there appears to be little reason to believe that female speed is the result of decreased accuracy. The literature on clerical speed tests indicates that females are not only faster than males but more accurate (Fairweather, 1976; Maccoby \& Jacklin, 1974). Previous research (Majeres, 1974) on identification of colors under somewhat similar conditions using a written response condition (writing newly learned, single-letter associates as a response, e.g., " $v$ " for red, " $x$ " for green, etc.) resulted in an uncorrected error rate of $.3 \%$, and $80 \%$ of these were made by males. Where subjects identified colors using the first letter of the color names, there were no uncorrected errors in over 4,000 responses. Although the precise role of uncorrected errors in the present work is not clear, they would appear to be of limited importance. In addition, since males tend to make more errors, they would be more likely to achieve faster times through uncorrected errors, thereby reducing the size of the sex difference.

Several lines of evidence along with the present results suggest that further work on sex differences in clerical speed should examine sex differences in verbal encoding when such encoding is directly related to response requirements. Clerical speed tests appear to have been inadequately described in the literature, with too much emphasis on perceptual encoding and attentional shifts. The clerical speed tests and such tests as the Digit Symbol Test have typically been regarded as nonverbal, perceptual-motor tests. It appears, at least in terms of the present results and interpretation, that sex differences on these tasks eventually may be accounted for in terms of sex differences in using verbal codes rather than sex differences in perceptual-motor skills.

\section{REFERENCES}

Anastasi, A. Differential psychology (3rd ed.), New York: MacMillan, 1958.

Barnsley, R. H., \& Rabinowitz, M. S. Handedness: Proficiency versus stated preference. Perceptual and Motor Skills, 1970, 30, 343-362.

Bennett, G. K., Seashore, H. G., \& Wesman, A. G. Differential aptitude tests. New York: Psychological, 1966.

Broverman, D. M., Klaiber, E. L., Kobayashi, Y., \& Vogel, W. Roles of activation and inhibition in sex differences in cognitive abilities. Psychological Review, 1968, 75, 23-50.

DAwson. J. L. M. Effects of sex hormones on cognitive style in rats and men. Behavior Genetics, 1972, 2, 21-42.

DroEge, R. C. Sex differences in aptitude maturation during high school. Journal of Counseling Psychology, 1967, 14, 407-411.

Dubors, P. H. The sex difference on the color-naming test. American Journal of Psychology, 1939, 52, 380-382.

Estes, W. K. Learning theory and intelligence. American Psychologist, 1974, 29, 740-749.

Fairweather, H. Sex differences in cognition. Cognition, 1976, 4, 231-280.

Fairweather, H., \& HutT, S. J. Sex differences in perceptualmotor skill in children. In C. Ounsted \& D. C. Taylor (Eds.), Gender differences: Their ontogeny and significance. London: Churchill Livingstone, 1972.

Fulkerson, F. E., \& Johnson, J. E. Methodological variables in verbal discrimination learning. Psychonomic Science, 1971, 22 , 68-69. 
Fulkerson, F. E., \& Prindayille, L. A. Effects of taxonomic instances as implicit associative responses on verbal discrimination learning. Journai of Experimental Psychology, 1973. 101, 383-385.

Garai, J. E., \& Scheinfeld, A. Sex differences in mental and behavioral traits. Genetic Psychology Monographs, 1968, 77, 169-299.

Gray. J. A., \& Buffery, A. H. W. Sex differences in emotional and cognitive behavior in mammals including man: Adaptive and neural bases. Acta Psychologica, 1971, 35, 89-111.

GUILFORD. J. P. The nature of human intelligence. New York: McGraw-Hill, 1967.

Hutr, C. Neuroendocrinological, behavioral, and intellectual aspects of sexual differentiation in human development. In C. Ounsted \& D. C. Taylor (Eds.), Gender differences: Their ontogeny and significance. London: Churchill Livingstone, 1972.

Jensen, A. R.. \& Rohwer, W. D., JR. The Stroop color-word test: A review. Acta Psychologica, 1966, 25, 36-93.

Maccoвy. E. E. (Ed.). The development of sex differences. Stanford: Stanford University Press, 1966.
Maccoby, E. E.. \& JACKIIN, C. N. The psychology of sex differences. Stanford: Stanford University Press, 1974.

Majeres, R. L. The combined effects of stimulus and response conditions on the delay in identifying the print color of words. Journal of Experimental Psychology, 1974, 102, 868-874.

NeIsser, U. Cognitive psychology. New York: Appleton-CenturyCrofts, 1967.

ROYER, F. L. Information processing of visual figures in the digit symbol substitution task. Journal of Experimental Psychology, $1971,87,335-342$.

Schneidler, G. R., \& Paterson, D. G. Sex differences in clerical aptitude. Journal of Educational Psychology, 1942, 33, 303-309.

Sichel, J. L., \& Chandler, K. A. The color-word interference test: The effects of varied color-word combinations upon verbal response latency. Journal of Psychology, 1969, 72, 219-231.

TYLER, L. E. Psychology of human differences. New York: Appleton-Century-Crofts, 1965.

(Received for publication January 13, 1977; accepted March 29, 1977.) 